\title{
Editorial
}

\section{Pasando el testigo}

Tras casi 20 años de andadura densa, y creemos que también productiva, ha llegado el momento de pasar el testigo a un nuevo Comité Editorial y decir adiós.

Oncología vio la luz en 1976. Entre 1983 y 1987 fue órgano de expresión de la Sociedad Española de Oncología (SEO), y de la Federación de Sociedades Españolas de Oncología (FESEO) entre 1987 y 1998. Desde 1999 hasta el momento actual ha venido publicándose como revista independiente.

La dirigieron desde 1976 a 1979 los Dres. Augusto Andrés y Pablo Viladiú y entre 1979 y 1986 lo hicieron los Dres. Ramón Pérez Carrión y José Ramón Germá. Desde entonces hasta ahora lo ha hecho el actual Comité Editorial, nombrado ex profeso por la FESEO, y cuyos miembros participamos también de forma directa en la constitución de las sociedades oncológicas, en la elaboración del primer libro blanco de la oncología española, en la creación de la FESEO y en la preparación de diferentes publicaciones oncológicas, dedicando particular atención a oncología y, como tales, hemos procurado actuar en cada momento como entendimos que más convenía a las inquietudes de todos nuestros colegas dedicados al quehacer oncológico.

A través del Índice Bibliográfico Español en Ciencias de la Salud (IBECS) y del proyecto Scientific Electronic Library Online/España (SciELO/España), oncología está teniendo ya el impacto internacional que todos deseábamos. Como colofón, en muy breve plazo, todos los artículos que se publiquen en oncología se recogerán en Medline y serán asequibles, de forma completa, a través de su red PubMed.

Antes de terminar, queremos manifestar nuestro agradecimiento a todos los oncólogos españoles que han colaborado de una forma continuada suministrando contenido a la revista, evaluando los trabajos y mostrando una fidelidad altamente encomiable en tiempos tan difíciles.

Queremos también hacer llegar nuestra gratitud a las personas que forman parte de la Editorial Alpe, que han procurado, no sin grandes dificultades, mantener la publicación a un nivel óptimo, sin escatimar esfuerzos para preservar su calidad, periodicidad y difusión. Una mención especial a Ángeles Álvarez que desde su incorporación a la revista en 1988 ha dado orden y estructura a cada número y ha colaborado de forma esencial a su proyección internacional.

Consideramos que hemos cumplido ampliamente los compromisos que adquirimos y que ha llegado el momento de ceder nuestra responsabilidad, apostando por la continuidad renovada de esta revista en las manos jóvenes y expertas del nuevo comité editorial. 